\title{
Critical evaluation of monoclonal antibody staining in breast carcinoma
}

\author{
D M PARHAM, G COGHILL, A J ROBERTSON \\ From the Department of Pathology, Ninewells Hospital and Medical School, Dundee, Scotland
}

SUMMARY The immunoperoxidase staining of 84 primary invasive breast carcinomas with four monoclonal antibodies (BRST-1, HMFG1, EMA, B72.3) was evaluated by semiquantitative light microscopical examination and quantitative image analysis. Major differences in the staining of the tumours for each of the monoclonal antibodies was observed. Correlation between monoclonal antibody staining and patient age, survival, histological grade, tumour diameter and cellularity was also carried out. This showed a significant association between histological grade and staining with BRST-1 and EMA.

The potential value of monoclonal antibodies in cancer has been widely investigated, and the immunoperoxidase localisation of monoclonal antibodies applied to tissue sections has found several applications. ${ }^{1}$ These include determination of the origin of metastatic tumours, the differential diagnosis of undifferentiated neoplasms, and the functional classification of malignancies. Other applications include the use of monoclonal antibodies to detect occult metastases or determine prognosis, and it is these roles that have attracted most attention in breast cancer. ${ }^{2-12}$

Monoclonal antibodies reactive against breast carcinoma have been produced using several different immunogens. These include breast carcinoma metastases, milk fat globule membranes, breast carcinoma cell lines, lymph nodes from patients who have had a mastectomy, cytoplasmic intermediate filaments and receptor proteins. $^{13}$ In this study we critically evaluated staining with four commercially available monoclonal antibodies, using both semiquantitative light microscopical examination and quantitative image analysis to minimise subjective bias.

\section{Material and methods}

Immunohistochemical staining was carried out on 84 cases of primary mammary carcinoma (ductal not otherwise specified) diagnosed and treated in Maryfield Hospital and Dundee Royal Infirmary in
1972 or 1973. Patient characteristics have previously been described ${ }^{12}$ and follow up for this study stopped in June 1987. Formalin fixed, paraffin wax embedded sections cut at $5 \mu \mathrm{m}$ were used. Sections for each monoclonal antibody were stained in a single batch to exclude any inherent variation in staining that inevitably arises between different batches of slides. The monoclonal antibodies used were BRST-1 (Ortho), HMFG1 (Oxoid), EMA (Dako), and B72.3 (Biogenesis). A preliminary study was carried out to determine the optimal concentrations of monoclonal antibody for staining.

Antibodies were localised by the avidin-biotin peroxidase label method (Vector Laboratories), ${ }^{14}$ binding resulting in a brown reaction product following oxidation of diaminobenzidine. Sections were counterstained with alum haematoxylin. During immunohistochemical processing, an occasional tissue section became unsuitable for analysis due to technical problems such as tissue floating off the slide or severe folding. For the reason given above it was not practicable to cut and stain additional sections for each case. Seventy eight cases were therefore analysed using BRST1, 82 using HMFG1, 78 using EMA and 81 using B72.3. There was no significant difference in age, tumour size, or survival of those who had surgery among the patients who had to be excluded.

Histological grade was assessed using the original sections stained with haematoxylin and eosin by the method devised by Bloom and Richardson ${ }^{15}$ and described in detail by Elston. ${ }^{16}$ The greatest tumour diameter was determined from the original pathology reports. 
ASSESSMENT OF MONOCLONAL

IMMUNOREACTIVITY

Light microscopy

Monoclonal antibody may be located within tumour cell cytoplasm, on the cell membrane, or outside the cell. For each of these locations the following three features were examined.

Distribution of staining: The tumours were assessed and scored as follows: (a) focal staining confined to a single high power field ( $\times 400)$, score 1 point; (b) nonuniform staining, at least two high power fields staining but separated by unstained areas, score 2 points; and (c) uniform staining, that is, staining at all high power fields, score 3 points.

Proportion of cells staining: This was performed in an area where the staining was most prominent at high power $(\times 400)$ over five fields. A score of 1 point was given when less than $50 \%$ of cells stained, 2 points when $50-80 \%$ stained, and 3 when more than $80 \%$ stained. For the extracellular category the number of deposits were counted for each high power field: less than five scored 1 point, five to 20 scored 2 points, and more than 20,3 points.

Staining intensity: This was graded as low (1 point) moderate ( 2 points), and high ( 3 points).

For each location within the tumour a cumulative score was obtained; this ranged from 0-9.

\section{Image analysis}

Image analysis was performed on the Quantimet 970 (Cambridge Instruments Ltd) as previously described. ${ }^{12}$ Three thresholds were used to detect labelled monoclonal antibody, malignant cells, and stroma. The area occupied by each component (total magnification $\times 80$ ) in a single field was determined. Section and staining artefacts were eliminated by electronic editing. The average result of 20 fields was determined and the area of malignant cells covered by labelled monoclonal antibody was expressed as a percentage (labelled percentage area).

Statistical analysis using the Wilcoxon signed rank test and Kendall's (tau) rank correlation was carried out on an IBM compatible personnel computer with Statgraphics software (Statistical Graphics Corporation, USA). A probability level of $\mathbf{0 . 0 0 1}$ or less was taken as being significant. ${ }^{17}$

\section{Results}

The visual assessment of staining showed that 77 out of 78 tumours stained with BRST-1, 78 out of 82 with HMFG1, 77 out of 78 with EMA and 68 out of 81 with B72.3. The results from the Quantimet (labelled percentage area) for the different monoclonal antibodies are shown in the figure. The box and whisper plot shows that the expression of monoclonal

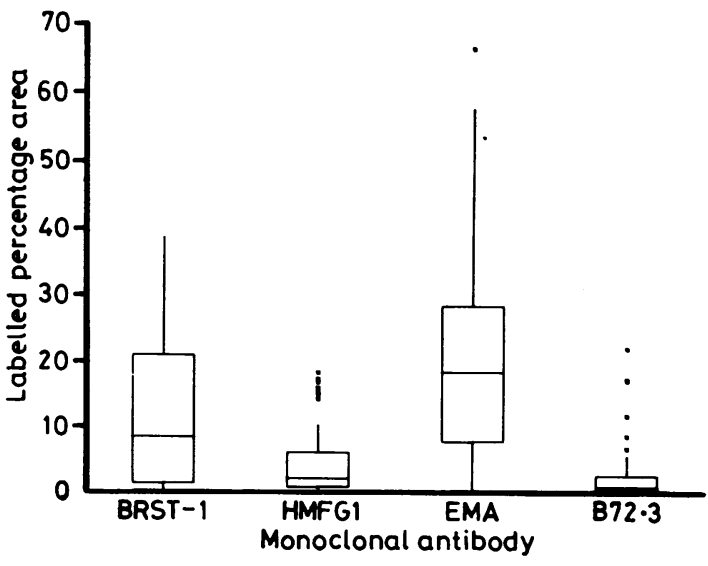

Figure Box and whisper plot showing distribution of staining in a series of mammary carcinomas with four different monoclonal antibodies.

antibody in this series of breast carcinomas was not uniform. Overall, staining of antigen detected by EMA was greatest (median 18.2\%, range 0-67.9\%). This was greater than the staining observed with BRST1 ( $p<0 \cdot 00001$ ). BRST1 expression ranged from 0-38.9\% (median $8 \cdot 1 \%$ ). HMFG1 expression ranged from $0-18.1 \%$ (median $1.7 \%$ ) and was significantly less than that observed with BRST-1 ( $<<0.00001)$. B72.3 staining was the weakest, ranging from $0-21.9 \%$ (median 0.44\%). Although B72.3 staining did not seem to be as strong as HMFG1 ( $p<0.004)$, this did not quite achieve significance. A similar pattern of results was obtained when subcellular staining was compared for different antibodies used (data not shown).

There was a good correlation between the Quantimet assessment of staining and membrane and cytoplasmic staining determined visually (table 1 ). The correlation between staining and different subcellular sites and methods of assessment for the different monoclonal antibodies in this group of tumours is shown in table 2.

A significant negative correlation was observed between BRST-1 staining and histological grade

Table 1 Correlation between Quantimet and visual assessment of immunoreactivity (Kendall's (tau) rank correlation)

\begin{tabular}{lllll}
\hline \multicolumn{5}{c}{ Quantimet assessment } \\
\cline { 2 - 5 } & $B R S T 1$ & $H M F G I$ & $E M A$ & $B 72.3$ \\
\hline Visual assessment & 0.48 & 0.68 & 0.58 & 0.51 \\
cytoplasm & $\mathrm{p}<0.0001$ & $\mathrm{p}<0.0001$ & $\mathrm{p}<0.0001$ & $\mathrm{p}<0.0001$ \\
Membrane & 0.58 & 0.58 & 0.41 & 0.47 \\
& $\mathrm{p}<0.0001$ & $\mathrm{p}<0.0001$ & $\mathrm{p}<0.0001$ & $\mathrm{p}<0.0001$ \\
\hline
\end{tabular}


Table 2 Correlation between staining by different monoclonal antibodies at different subcellular sites and by different methods of assessment

\begin{tabular}{llll}
\hline & $H M F G 1$ & $E M A$ & $B 72.3$ \\
\hline BRST-1: & & & \\
Quantimet values & 0.15 & 0.38 & 0.14 \\
& $\mathrm{p}=0.05$ & $\mathrm{p}<0.0001$ & $\mathrm{p}<0.07$ \\
Cytoplasm & 0.14 & 0.48 & 0.24 \\
Membrane & $\mathrm{p}<0.07$ & $\mathrm{p}<0.0001$ & $\mathrm{p}<0.002$ \\
& 0.31 & 0.36 & 0.18 \\
HMFG1: & $\mathrm{p}<0.0001$ & $\mathrm{p}<0.0001$ & $\mathrm{p}<0.02$ \\
Quantimet values & & 0.27 & 0.33 \\
Cytoplasm & & $\mathrm{p}<0.0005$ & $\mathrm{p}<0.0001$ \\
Membrane & & 0.38 & 0.22 \\
EMA: & & $\mathrm{p}<0.0001$ & $\mathrm{p}<0.003$ \\
Quantimet values & & 0.26 & 0.36 \\
Cytoplasm & & $\mathrm{p}<0.0004$ & $\mathrm{p}<0.0001$ \\
Membrane & & & 0.37 \\
& & & $\mathrm{p}<0.0001$ \\
& & & 0.34 \\
\hline
\end{tabular}

Table 3 Correlation between staining and differentiation with monoclonal antibody BRST-1

\begin{tabular}{llll}
\hline & \multicolumn{3}{l}{ Method of assessment } \\
\cline { 2 - 4 } & Quantimet & Cytoplasm & Membrane \\
\hline Grade & -0.32 & -0.05 & -0.41 \\
& $\mathrm{p}<0.0001$ & $\mathrm{p}<0.6$ & $\mathrm{p}<0.0001$ \\
\hline
\end{tabular}

(table 3). This was confined to assessment by the Quantimet and by visual assessment of membrane staining. A similar negative correlation was observed between membrane staining by EMA and histological grade $(-0.41, \mathrm{p}<0.001)$. Apart from these findings, no significant correlation was observed between monoclonal antibody staining and survival, age, tumour diameter or cellularity (data not shown).

Extracellular staining showed no correlation between any of the variables assessed. The formation of a staining index derived from a combination of the cytoplasm and membrane scores did not change the above findings.

\section{Discussion}

Most of the neoplasms stained with each of the four monoclonal antibodies and this accords with previous studies. ${ }^{891218-20}$ The poorest staining was observed with B72.3 when only 68 out of 81 tumours were positive. Our results show considerable differences in staining among different monoclonal antibodies in the group of breast neoplasms studied. These differences are most easily appreciated by studying the results obtained from the Quantimet. There was a good correlation between the Quantimet assessment of monoclonal antibody staining and membrane or cytoplasmic staining determined visually. No correlation, however, was observed between extracellular staining and all of the variables measured. Extracellular staining formed only a minor part of total tumour staining and was difficult to quantify reliably by light microscopical examination. Furthermore, staining deposits tended to occur in areas where the pattern of fibrosis suggested recent necrosis and as such probably does not represent true extracellular secretion.

Two of the antibodies used were raised against milk fat globule membranes (HMFG1, anti-EMA), ${ }^{21}$ one was raised against cell membranes derived from breast carcinoma metastases (B72.3) ${ }^{18}$ and the fourth against a breast carcinoma cell line (BRST1).$^{20}$ Little is known about the relations of the epitopoes against which these monoclonal antibodies are directed, but all are immunoreactive against glycoproteins ${ }^{1320}{ }^{23-25}$ present in the cell cytoplasm and on cell membranes. It is thought that HMFG1 reacts against a different antigenic site on the same molecule to which EMA is directed ${ }^{26}$ The other monoclonal antibodies may have a similar relation with this molecule. This would explain the positive correlation between EMA expression and the staining by other antibodies. If the antigen determinant to which EMA is directed also has a central role in the formation of this molecule, and the other epitopes are more variable and more vulnerable to the malignant process, this would explain the poorer correlation observed in staining among the other monoclonal antibodies.

A significant negative correlation was observed between BRST-1 (Quantimet and membrane) staining and tumour differentiation, as assessed by histological grade. BRST-1 staining was greatest in well differentiated tumours (grade 1) and least in poorly differentiated ones (grade 3). EMA staining of cell membranes was also related to differentiation, although this only just reached significance. No correlation between staining by any of the monoclonal antibodies and survival was observed.

The absence of any association between monoclonal antibody expression and survival was not unexpected. A previous study found that absence of HMFG1 expression was associated with a poor prognosis and extracellular deposits with a favourable outcome when correlated against remission. ${ }^{8}$ Other authors, however, were unable to show any association with patient survival. ${ }^{12}$ Ellis et $a l$, using a monoclonal antibody (NCRC 11) raised to human milk fat globule membrane, found a positive correlation between the degree of staining and survival. ${ }^{27-29}$ Wright $e t$ al were unable to reproduce these findings. ${ }^{30}$ Possible explanations for the lack of consistency in these studies may include variations among laboratories in the preparation of 
stained tissue sections and the methods of patient follow up.

We thank Professor J S Beck for his encouragement throughout this study. This work was supported by a grant from Tayside Health Board.

\section{References}

1 Heyderman E. Tumour Markers. In: Polak JM, Van Noorden D, eds. Immunocytochemistry: modern methods and applications. Bristol: John Wright \& Sons Ltd, 1986:502-32.

2 Dearnaley DP, Sloane JP, Ormerod MG, et al. Increased detection of mammary carcinoma cells in marrow smears using antisera to epithelial membrane antigen. Br J Cancer 1981;44:85-90.

3 To A, Coleman DV, Dearnaley DP, Ormerod MG, Steele K, Neville AM. Use of antisera to epithelial membrane antigen for the cytodiagnosis of malignancy in serous effusions. $J$ Clin Pathol 1981;34:1326-32.

4 Epenetos AA, Canti G, Taylor-Papadimitriou J, Curling M, Bodmer WF. Use of two epithelium-specific monoclonal antibodies for diagnosis of malignancy in serous effusions. Lancet 1982;ii:1004-6.

5 Johnston WW, Szpak CA, Chase Lottich S, Thor A, Schlom J. Use of a monoclonal antibody (B72.3) as an immunocytochemical adjunct to the diagnosis of adenocarcinoma in human effusions. Cancer Res 1985; 45:1894-900.

6 Cote RJ, Rosen PP, Hakes TB, et al. Monoclonal antibodies detect occult breast carcinoma metastases in bone marrow of patients with early disease. Am J Surg Pathol 1988;12:333-40.

7 Thor A, Viglione MJ, Ohuchi N, et al. Comparison of monoclonal antibodies for the detection of occult breast carcinoma metastases in bone marrow. Breast Cancer Res Treat 1988;11:133-45.

8 Wilkinson MJS, Howell A, Harris M, Taylor-Papadimitriou J, Swindell R, Sellwood RA. The prognostic significance of two epithelial membrane antigens expressed by human mammary carcinomas. Int J Cancer 1984;33:299-304.

9 Berry N, Jones DB, Smallwood J, Taylor I, Kirkham N, TaylorPapadimitriou J. The prognostic value of the monoclonal antibodies HMFG1 and HMFG2 in breast cancer. Br J Cancer 1985;51:179-86.

10 Ellis IO, Hinton CP, Macnay J, et al. Immunohistochemical staining of breast carcinoma with the monoclonal antibody NCRC11: A new prognostic indicator. Br Med J 1985;290: 881-3.

11 Wright C, Angus B, Wetherall M, et al. Prognostic factors in breast cancer: Immunohistochemical staining for SPI and NCRC11 related to survival, tumour epidermal growth factor receptor and estrogen receptor status. J Pathol 1987;153:325-31.

12 Parham DM, Slidders W, Robertson AJ. Quantitation of human milk fat globule (HMFG1) expression in breast carcinoma and its association with survival. J Clin Pathol 1988;41:875-9.

13 Thor A, Weeks MO, Schlom J. Monoclonal antibodies and breast cancer. Semin Oncol 1986;13:393-401.

14 Coggi G, Dell'Orto P, Viale G. Avidin-biotin methods. In: Polak JM, Van Noorden D, eds. Immunocytochemistry: modern methods and applications. Bristol: John Wright \& Sons Ltd, 1986:54-70.

15 Bloom HJG, Richardson WW. Histological grading and prognosis in breast cancer. Br J Cancer 1957;11:359-77.

16 Elston CW. Assessment of histological grade in human breast cancer. In: Blamey RW, ed. Seminar in breast cancer. London: Update Publications, 1984:47-50.
17 Brown RA, Swanson Beck J. Statistics on microcomputers: A nonalgebraic guide to their appropriate use in biomedical research and pathology laboratory practice. IV. Correlation and regression. J Clin Pathol 1989;42:4-12.

18 Nuti M, Teramoto YA, Mariani-Costantini R, Horan Hand P, Colcher D, Schlom J. A monoclonal antibody (B72.3) defines patterns of distribution of a novel tumor-associated antigen in human mammary carcinoma cell populations. Int $J$ Cancer 1982;29:539-45.

19 Sloane JP, Hughes F, Ormerod MG. An assessment of the value of epithelial membrane antigen and other epithelial markers in solving diagnostic problems in tumour histopathology. Histochem J 1983;15:645-54.

20 Mesa-Tejada R, Palakodety RB, Leon JA, Khatcherian AO, Greaton CJ. Immunohistochemical distribution of a breast carcinoma associated glycoprotein identified by monoclonal antibodies. Am J Pathol 1988;130:305-14.

21 Taylor-Papadimitriou J, Peterson JA, Arklie J, Burchell J, Ceriani RL, Bodmer WF. Monoclonal antibodies to epithelium-specific components of the human milk fat globule membrane: production and reaction with cells in culture. Int $J$ Cancer 1981;28: 17-21.

22 Heyderman E, Strudley I, Powell G, Richardson TC, Cordell JL, Mason DY. A new monoclonal antibody to epithelial membrane antigen (EMA)-E29. A comparison of its immunocytochemical reactivity with polyclonal anti-EMA antibodies and with another monoclonal antibody, HMFG2. Br J Cancer 1985;52:355-61.

23 Ormerod MG, Steele K, Westwood JH, Mazzini MN. Epithelial membrane antigen: Partial purification, assay and properties. Br J Cancer 1983;48:533-41.

24 Burchell J, Durbin H, Taylor-Papadimitriou J. Complexity of expression of antigenic determinants, recognised by monoclonal antibodies HMFG-1 and HMFG2, in normal and malignant human mammary epithelial cells. J Immunol 1983;131:508-13.

25 Johnson AG, Schlom J, Paterson AJ, Bennet J, Magnani JL, Colcher D. Analysis of human Tumour-associated Glycoprotein (TAG-72) identified by monoclonal antibody B72.3. Cancer Res 1986;46:850-7.

26 Ormerod MG, McIlhinney J, Steele K, Shimizu M. Glycoprotein PAS-O from milk fat globule membrane carries antigenic determinants for epithelial membrane antigen. Mol Immunol 1985;22:265-9.

27 Ellis IO, Robins RA, Elston CW, Blamey RW, Ferry B, Baldwin RW. A monoclonal antibody, NCRC-11, raised to human breast carcinoma. 1 Production and immunohistological characterization. Histopathol 1984;8:501-16.

28 Ellis IO, Hinton CP, Macnay J, et al. Immunocytochemical staining of breast carcinoma with the monoclonal antibody NCRC11: A new prognostic indicator. $\mathrm{Br} \mathrm{Med} J$ 1985;290: 881-3.

29 Ellis IO, Bell J, Todd JM, et al. Evaluation of immunoreactivity with monoclonal antibody NCRC 11 in breast carcinoma. Br J Cancer 1987;56:295-9.

30 Wright C, Napier J, Wetherall M, et al. Prognostic factors in breast cancer: Immunohistochemical staining for SPI and NCRC11 related to survival, tumour epidermal growth factor receptor and oestrogen receptor status. J Pathol 1987;153:325-31.

Requests for reprints to: Dr D M Parham, Department of Pathology, Ninewells Hospital \& Medical School, Dundee, Scotland, DD1 9SY. 